\title{
Land use cover change has non-trivial and potentially dominant impact on global gross primary productivity (2000-2100)
}

Haiyan Hou

East China Normal University https://orcid.org/0000-0002-3052-1259

Bing-Bing Zhou

Ocean University of China https://orcid.org/0000-0002-6486-4743

Fengsong Pei

Jiangsu Normal University

Guohua Hu

East China Normal University

Zhongbo Su

Faculty of Geo-Information Science and Earth Observation (ITC), University of Twente

\section{Yijian Zeng}

University of Twente

Han Zhang

School of Geographic Sciences, East China Normal University

\section{Yukun Gao}

East China Normal University

Meng Luo

East China Normal University

Xia Li (D lixia@geo.ecnu.edu.cn)

East China Normal University https://orcid.org/0000-0003-3050-8529

\section{Article}

Keywords: land use/cover change, gross primary productivity, sustainability

Posted Date: September 21st, 2021

DOI: https://doi.org/10.21203/rs.3.rs-902420/v1

License: (1) (1) This work is licensed under a Creative Commons Attribution 4.0 International License.

Read Full License 


\section{Abstract}

Anthropogenic land use/cover (LULC) change alters terrestrial gross primary productivity (GPP), which is a major atmospheric carbon sink. Identifying the impacts of future LULC changes on terrestrial GPP has been challenging due to the complexity of incorporating future LULC into ecosystem models. Here, we present eight-scenario-based projections of global spatially explicit LULC at $1 \mathrm{~km}$ resolution over the period 2015-2100. We further conducted Fourteen experiments to quantify the contribution of LULC change to GPP dynamics relative to that of climate change under different scenarios. We find that global GPP change would be underestimated by $10.92 \%-16.16 \%$ during $2000-2050$ and $1.41 \%-14.57 \%$ during 2050-2100 when modeled without LULC dynamics-as in most existing GPP modeling efforts.

Particularly, LULC-change-dominated areas would account globally for 1.65-2.20 the size of the Amazon rainforest. Our findings underline the necessity of incorporating future LULC dynamics into process-based models and highlight the non-trivial role of LULC in transitioning toward sustainability.

\section{Introduction}

The global terrestrial carbon uptake is estimated to be $\sim 3.2 \pm 0.7 \mathrm{Pg} \mathrm{C}$ per year and offsets one-third of anthropogenic carbon emissions ${ }^{1}$. It is primarily determined by the carbon flux connecting the atmosphere and the biosphere-photosynthetic carbon fixation by terrestrial ecosystems-also known as gross primary production (GPP) ${ }^{2}$. Besides, GPP is a fundamental ecosystem process that supports ecosystem functioning such as respiration and growth and provides food, fiber, and wood to humans and other terrestrial species ${ }^{3}$. GPP is also relevant to ecosystem resilience and self-regulation for it controls nutrient cycles and the build-up of organic material ${ }^{4}$. Therefore, GPP research has been gaining increasing interest in the past three decades, especially in global change studies ${ }^{5,6}$.

Notable progress has been made to quantify GPP with observations at the site scale or model-based estimates at the ecosystem or global scales ${ }^{7}$. In particular, model-based quantification of global GPP dynamics is critical for assessing how GPP is regulated by multiple interacting environmental factors, such as climate, atmospheric $\mathrm{CO}_{2}$ concentration, and land use/cover (LULC) ${ }^{8}$. In this vein, existing studies focus mostly on historical assessments at the regional and global scales ${ }^{8,9,10}$, with inconclusive findings of which aspect dominates GPP dynamics. To date, studies of future global GPP dynamics remain rather limited, let alone disentangling the relative contributions of main environmental driving factors.

A major methodological challenge to assessing and understanding future global GPP dynamics lies in integrating future LULC projections -although LULC change is expected to greatly affect terrestrial GPP by altering vegetation structure and soil properties, and can feedback to atmospheric $\mathrm{CO}_{2}$ concentrations and regional climate on different spatiotemporal scales ${ }^{11}$. Until recently, LULC in most relevant studies has often been simplified as a static land surface parameter in Land Surface Models (LSMs) to express the distribution of vegetation and often with low spatial resolutions ${ }^{12}$. Treating LULC in such a simplistic way may induce significant uncertainties in long-term GPP estimation, which remains to be studied. Thus, 
calls have been made for developing global datasets of LULC projections that incorporate human activities (e.g., social-economic development and carbon emissions) to better understand the patterns and drivers of future global GPP dynamics ${ }^{13}$.

Fortunately, scholarly inputs in producing such future global LULC projections have been accumulating. For instance, Li et al. ${ }^{14}$ published a global LULC dataset at the 1-km resolution for 2010-2100 that considers four scenarios based on the Intergovernmental Panel on Climate Change Special Report on Emission Scenarios ${ }^{15}$. Lately, the Land Use Harmonization (LUH2) project proposed a standard global LULC dataset at the $0.25^{\circ}$ resolution for 2015-2100 based on the coupled Shared Socioeconomic Pathways (SSPs) and Representative Concentration Pathways (RCPs) scenario framework ${ }^{16,17,18}$. The LUH2 dataset is well received within the global change research community for century-scale LULC-based studies. Yet, the coarse resolution of this dataset makes it almost impossible to reflect detailed LULC changes (e.g., urban and cropland expansion) and may result in over- or under-estimation of carbon emissions $^{19}$. Also, the classification scheme of the LUH2 dataset cannot be readily applied to many $\mathrm{LSMs}^{20}$. Efforts have been made to downscale the LUH2 dataset based on plant functional types (PFT), though still at a relatively coarse resolution (e.g., $0.05^{\circ}$ resolution in Chen et al. ${ }^{20}$ ) or focusing on a regional scale (e.g., China in Liao et al. ${ }^{21}$ ).

With the foregoing, the present study attempts to: (1) produce a 1-km resolution global LULC dataset for 2015-2100 by downscaling the LUH2 dataset with the Future Land Use Simulation (FLUS) model ${ }^{14}$ based on the International Geosphere-Biosphere Programme (IGBP) classification scheme; (2) integrate this fineresolution LULC dataset into a process-based Common Land Model (CoLM) ${ }^{22}$ for quantifying the spatial patterns and temporal dynamics of the global GPP; and further (3) disentangle the relative contributions of climate and LULC changes to future GPP dynamics via numerical experiments of 14 SSP and/or RCP scenarios. The 1-km resolution LULC dataset generated from this study can contribute to the for centuryscale Earth system modeling studies. Equally importantly, our GPP simulation experiments quantitatively reveal that LULC change is a secondary yet significant driver of future global GPP dynamics compared to climate change. Such relative contributions of the LULC and climate changes exhibit remarkable spatial heterogeneity and a potential temporal shift, highlighting critical implications for improving LULC-based policies toward a carbon-neutral future.

\section{Results}

\section{Projected global LULC changes under eight coupled SSP-RCP scenarios}

The global trends of future LULC changes over the 21 st century are consistent between our projections and the LUH2 projections under the eight SSP-RCP scenarios (Fig. 1; Supplementary Figs. 1-6 for details of the global LULC changes). In both predictions, most terrestrial Earth would be covered by grassland, followed by forested land and then cropland, bare land and lastly, urban land. The minor quantitative differences lie in that our projections of forested land and cropland are smaller than the LUH2 projections 
whereas our projections of grassland, bare land, and urban land are slightly larger. Notably, qualitative differences do exist for each LULC type under certain scenarios. For example, grassland is projected (by FLUS) to increase under SSP3-RCP7.0 versus the projected decrease by LUH2. Forested land by FLUS is to experience a sharp decline before 2050 under SSP2-RCP4.5, while there is an only gentle decline trajectory by LUH2. Cropland is forecast by FLUS to have a slight increase under SSP3-RCP7.0, in contrast to the drastic growth projected by LUH2. Bare land is forecast by FLUS to decrease sharply by 2050 and then expand under SSP2-RCP4.5, instead of the continued decline trend as projected by LUH2. Particularly, urban land is forecast by FLUS to keep its rapid growth trend after 2050 under the eight scenarios, rather than the slowdown growth or even a decrease trend (under SSP1-RCP1.9 and SSP1$\mathrm{RCP} 2.6)$ in $\mathrm{LUH} 2$ projections.

In general, both our FLUS projections and the LUH2 projections show that the global trends of future LULC changes are susceptible to the socioeconomic pathways the global community decides to take, and that year 2050 could be the tipping point for critical changes (Fig. 1). For instance, following a sustainable development and low carbon emission pathway (SSP1-RCP1.9 and SSP1-RCP2.6), the global forest would generally increase and the bare land rather stable, while the urban and cropland would gain mild growth at largely the cost of grassland. Alternatively, if a regional rivalry and high-emission pathway were to be taken (SSP3-RCP7.0), the global bare land would experience the most decline and forested land also drastic loss, while urban land would gain the least growth with grassland and cropland mildly increasing. Furthermore, coupling global inequality or fossil-fueled development scenarios (SSPs 4-5) with RCPs adds new complications. For one, in an inequality world with high adaption to climate change in developing countries (SSP4), the global land system would be featured by the increase of urban land and decrease of bare land when coupled with RCP3.4 or RCP6.0. Yet, the future trajectories of global grassland, forest, and cropland would go opposite trends in the two coupled representative concentration pathways. For another, although the global land system under SSP5-RCP3.4 and SSP5-RCP8.5 would be featured by the similar trends of rapid urban growth, stable bare land, and mild forest loss, there would be a drastic conversion from grassland to cropland after 2050 under SSP5-RCP3.4, in contrast to the gentle trends of mild grassland loss and cropland gain under SSP5-RCP8.5. Finally, in the middle of the road scenario (SSP2-RCP4.5), the future global LULC changes would be featured by modest increases of cropland and urban land and the rapid decrease of grassland, while forest and bare land would first decrease until 2050 and then increase for the second half of the 21st century. Although changes in the spatial pattern of the simulated LULC could be barely noticeable at the global scale (Fig. 2), the structural changes of the global land system could still lead to pronounced social-environmental consequences at the regional and global scales, depending on future development pathways.

\section{Projected future global GPP dynamics driven by LULC changes}

The global trend of projected GPP dynamics over the 21 st century is strongly affected by future LULC changes under the eight coupled scenarios (Fig. 3). Historically, our simulation shows that the LULC changes during 2000-2015 reduced the global GPP by $568.10 \mathrm{Tg} \mathrm{C}$, a $0.35 \%$ loss. In a sustainable future, the trend would remain largely stable during 2015-2100, as the Mann-Kendall test detects statistically 
significant yet minor temporal changes in SSP1-RCP1.9 and SSP1-RCP2.6 (+2.99 $\mathrm{Tg} \mathrm{C} \mathrm{yr}^{-2}, p=0.006$; $\left.+0.97 \mathrm{Tg} \mathrm{C} \mathrm{yr}^{-2}, p=0.08\right)$. In the other six unsustainability scenarios, contrastingly, the total amount of the global GPP would experience dramatic changes over the 21st century, and the year 2050 could be a tipping point of shifting trends. The most dramatic decline of the global GPP occurs in a future of inequality with a stringent mitigation policy (SSP4-RCP3.4), while the total amount of the global GPP in the other five scenarios either shows a slowdown of decrease during 2050-2100 or shifts to an increasing trend after 2050 mainly due to the forest restoration. Generally speaking, under these six scenarios, the projected global GPP loss during 2015-2050 ranges from -30.27 to $-11.84 \mathrm{Tg} \mathrm{C} \mathrm{yr}^{-2}$, and the change during 2050-2100 ranges from -40.78 to $+22.96 \mathrm{Tg} \mathrm{C} \mathrm{yr}^{-2}$. As compared to 2015-2050, the impact of future LULC changes on the global GPP trend has remarkable uncertainties and even directional differences during 2050-2100. This indicates potentially huge environmental degradation risks and, simultaneously, a vast window of human interventions for sustainability in the second half of the 21 st century.

Because of the possibility of nonlinear GPP trajectories, the nonparametric Sen's slope was computed for each grid to assess its median annual GPP change. The computation was based on the GPP projections of each grid for every five years from 2015 to 2100 . The slope shows strong spatial heterogeneity of the projected future global GPP dynamics driven by LULC changes (Fig. 4). Although most of the world would experience minor GPP changes (i.e., gray areas) in all the LULC scenarios, noticeable regional variations exist among the areas with significant GPP changes (e.g., blue and red areas). For example, in the scenarios of no aggressive development but with strict policy enforcement regarding vegetation protection or vegetation regrowth (i.e., SSP1-RCP1.9, SSP1-RCP2.6, and SSP2-RCP4.5), the projected global GPP at 2100 is slightly higher than the 2015 GPP (Fig. 3). In these three scenarios, the main GPP gainers include the Amazonia, Equatorial Afrotropics, southeast Asian forests, and west boreal forests, and the main GPP losers include the northeast American forests, southeast U.S. savannas and forests, Greater European forests, central east Asian forests, Brazil Cerrado and Atlantic coast, South American grasslands, and central Afrotropics (Figs. 4 a, b, and e). In the other five unsustainability scenarios with net global GPP loss during 2015-2100 (Fig. 3), the distribution of the GPP gainers and losers shows similar spatial patterns (Figs. $4 \mathrm{~d}$ and f-h). Yet, the area of these gainers slightly shrinks and that of the losers noticeably expands, which is particularly dramatic in a future world of inequality with relatively low carbon emissions (Fig. 4c, SSP4-RCP3.4).

These main gainers and losers-which form five GPP change hotspot areas, i.e., Eastern North America, Central South America, Europe, Central Africa, and East and Southeast Asia-were further examined to compare their simulated GPP trends under the eight LULC scenarios (Fig. 5). Our results show that these hotspot areas also have high GPP. The estimated GPP in 2015 shows that the five regions have an average GPP of around $2000 \mathrm{~g} \mathrm{C} \mathrm{m}^{-2} \mathrm{yr}^{-1}$ or above, except that Europe has close to $1000 \mathrm{~g} \mathrm{C} \mathrm{m}^{-2} \mathrm{yr}^{-1} \mathrm{GPP}$. Unfortunately, in most of the eight LULC scenarios, the five hotspot areas would experience GPP loss of varying degrees. The ranges of simulated GPP dynamics in the Eastern North America, Central South America, Europe, Central Africa, and East and Southeast Asia are $-85.06 \sim-8.82 \mathrm{~g} \mathrm{C} \mathrm{m}^{-2}(-4.11 \%$ 
$-0.43 \%),-32.14 \sim+7.29 \mathrm{~g} \mathrm{C} \mathrm{m}^{-2}(-3.34 \% \sim+0.76 \%),-185.20 \sim+19.21 \mathrm{~g} \mathrm{C} \mathrm{m}^{-2}(-6.49 \% \sim+0.67 \%)$, $-33.60 \sim+80.03 \mathrm{~g} \mathrm{C} \mathrm{m}^{-2}(-1.28 \% \sim+3.05 \%)$, and $-49.28 \sim+8.19 \mathrm{~g} \mathrm{C} \mathrm{m}^{-2}(-2.58 \% \sim+0.43 \%)$, respectively. The worst case of a $-185.20 \mathrm{~g} \mathrm{C} \mathrm{m}^{-2}(-6.49 \%)$ GPP loss would occur in East and Southeast Asia due to the biofuel plant under the SSP4-RCP3.4 scenario. Under this very scenario, contrastingly, Central South America would potentially gain the highest GPP of $+80.03 \mathrm{~g} \mathrm{C} \mathrm{m}^{-2}(+3.05 \%)$ through vegetation regrowth. This contrast again suggests that there is no panacea but place-based actions to mitigate GPP loss and even increase regional GPP.

\section{Projected future global GPP dynamics driven by climate and LULC changes}

The global trend of projected GPP dynamics over the 21st century is strongly dependent on future climate policies we shall take (i.e., RCPs), as indicated by the contrasting GPP trends in the simulation experiments with constant LULC and different climate forcing (Fig. 6 dashed lines). Interestingly, the GPP trends simulated with both climate and LULC changes (Fig. 6 solid lines) are similar and close to the results based on only changing climate forcing (dashed lines). The two observations suggest that future global GPP dynamics would be more influenced by climate change than LULC change. Among the three scenarios of concurrent climate and LULC changes (i.e., Clim45-LULC245, Clim60-LULC460, and Clim85LULC585), the most dramatic GPP loss would occur under the climate forcing of RCP8.5 and LULC of SSP5-RCP8.5 (i.e., Clim85-LULC585), which could reduce the global GPP by $-17.32 \mathrm{Pg}$ C from 2015 to $2100,-10.75 \%$ of the 2015 global total. The dramatic GPP loss in a future with high energy demand and carbon emissions yet without any climate mitigation policy (i.e., RCP8.5) would become increasingly divergent from the GPP trajectories under the other two scenarios from 2050 onward, indicating a potential risk of locked-in environmental degradation that may be addressed with fewer policy efforts before 2050 .

Although the global GPP is projected to decrease over the 21st century at the three levels of climate forcing (i.e., RCP4.5, RCP6.0, and RCP8.5), strong spatial heterogeneity stands out in terms of the climate change impact on future GPP dynamics, as measured by the Sen's slope denoting the annual GPP change at a grid-scale (Fig. 7). Unlike the spatial pattern of the LULC change impact on future GPP dynamics, which is mostly minor (Fig. 4), the majority of the world would experience non-trivial GPP changes at the three levels of climate forcing (Fig. 7 non-gray areas), with GPP-stable areas mostly located at the desert areas (gray areas). This contrast corroborates the finding that future climate change would be more impactful than LULC change on global GPP dynamics. Another corroboration emerges from two other observations-LULC change would not notably affect the global pattern of projected annual GPP change (compare Fig. 7 subfigures horizontally), while climate change would expand GPP loss areas markedly (vertical comparisons). Generally speaking, the global patterns of projected annual GPP change under the three levels of climate forcing are consistently featured by GPP gains in those temperature-limited high-latitude/altitude areas (e.g., Russia, Canada, American West, and Andes \& Pacific Coast) and humidity-limited semi-arid grasslands (e.g., Mongolian Grasslands and Australian Savannas), contrasting to GPP losses in mostly the tropical rain forest and temperate forest areas (e.g., Amazonia, Central America, Equatorial Afrotropics, Greater European Forest, Southeast Asian Forests, 
Malaysia \& Western Indonesia, and Australian Islands \& Eastern Indonesia). In particular, with the highest considered climate forcing (i.e., under RCP8.5), the areas with dramatic GPP loss would expand remarkably in the Amazonia and Central America (Fig. 7 dark blue areas).

\section{Relative contributions of climate and LULC changes to global GPP dynamics}

To quantitatively compare the respective impacts of climate and LULC changes on global GPP dynamics during 2000-2100, we adopted a contribution decomposition methodology (see Methods) to disentangle their relative contributions (and residual effects) at each $0.5^{\circ}$ grid under three matched scenarios (i.e., Clim45-LULC245, Clim60-LULC460, and Clim85-LULC585; Fig. 8). Unsurprisingly, the contribution of LULC change to GPP dynamics during 2000-2100 is little or minor (i.e., contribution less than $10 \%$ ) for $54 \%$ $56 \%$ of the global terrestrial area in the three scenarios. Further, $7 \% \sim 9 \%\left(9,054,884 \sim 12,092,465 \mathrm{~km}^{2}\right)$ would have LULC change dominating the global GPP dynamics (i.e., contribution over $50 \%$, Figs. $8 \mathrm{a}$, b, and c). Contrastingly, $75 \% \sim 77 \%$ of the terrestrial area would have climate change as the dominant driver (Figs. $8 d$, e, and f), and $12 \%$ of the global terrestrial area, mostly deserts, has stable negligible GPP changes-suggesting that although secondary to the impact of climate change on global GPP dynamics, the impact of LULC change is by no means trivial (cf., $7 \%$ ). Spatially, the places with LULC change dominating GPP dynamics are rather fragmented, and seem to be mostly located at the margins of global deserts or the frontiers of global urbanization in especially coastal areas and central Africa. The area of such places does not increase proportionately with the increasing level of climate forcing, nor does their spatial pattern notably change with the three scenario settings (Figs. 8a, b, and c). The relatively stable spatial distribution of such LULC-change-dominated places suggests that proactive land management policymaking in these areas could be fruitful.

Of equal importance for human interventions are the five GPP change hotspot areas, i.e., East North America, Central South America, Europe, Central Africa, and East and Southeast Asia (same as those in Fig. 5), about which there are two observations worth-noting. For one, the contribution of LULC change to GPP dynamics in each hotspot is generally smaller in 2000-2050 than in 2050-2100 under the three matched climate-LULC change scenarios (Table 1). There are five exceptions, though: Europe and East and Southeast Asia under Clim60-LULC460, and Central South America, Europe, and Central Africa under Clim85-LULC585. For the other, the general temporal pattern of these five areas is opposite from that of the globe, for which LULC change is more impactful on GPP dynamics in the first half of the 21 st century under all three scenarios. The contrast suggests that LULC change monitoring and management in these GPP change hotspot areas alone is insufficient for maintaining terrestrial carbon balance. Nonetheless, LULC change in these five hotspots could make a striking impact on GPP dynamics in a few cases. For instance, the relative contribution of LULC change in East and Southeast Asia could hit $56.08 \%$ in 2050 2100 under Clim45-LULC245, Central Africa for 34.99\% under Clim60-LULC460, Central South America for 28.49\% and 24.56\% under Clim45-LULC245 and Clim60-LULC460, respectively. For the globe, however, the contribution of LULC change is estimated to reach $16.16 \%, 14.22 \%$, and $10.92 \%$ in $2000-2050$ under Clim45-LULC245, Clim60-LULC460, and Clim85-LULC585, respectively-in stark contrast to the corresponding $14.57 \%, 1.41 \%$, and $1.74 \%$ in $2050-2100$. The message is clear: the window of LULC-based 
solutions to build a carbon-neutral world is quickly vanishing, and the GPP change hotspot areas are insufficient for land policy interventions.

Table 1 Relative contributions of LULC change to GPP dynamics (\%) under Clim45-LULC245, Clim60LULC460, and Clim85-LULC585 in five GPP change hotspots and for the globe, for 2000-2050 and 20502100. Note that the five hotspots are consistent with those in Fig. 5.

\begin{tabular}{lllllll}
\hline & \multicolumn{2}{l}{ SSP2-RCP4.5 } & \multicolumn{2}{l}{ SSP4-RCP6.0 } & \multicolumn{2}{l}{ SSP5-RCP8.5 } \\
\cline { 2 - 6 } Eastern North America & $2000-2050$ & $2050-2100$ & $2000-2050$ & $2050-2100$ & $2000-2050$ & $2050-2100$ \\
Europe & 2.19 & 5.56 & 0.25 & 15.4 & 1.58 & 8.73 \\
East and Southeast Asia & 17.34 & 6.91 & 4.15 & 2.02 & 7.08 & 4.09 \\
Central South America & 7.96 & 56.08 & 15.35 & 1.37 & 13.19 & 14.31 \\
Central Africa & 0.08 & 5.14 & 5.19 & 34.99 & 3.97 & 3.6 \\
Globe & 16.16 & 14.57 & 14.22 & 1.41 & 10.92 & 1.74 \\
\hline
\end{tabular}

\section{Discussion}

In this study, we first employed FLUS to downscale the $0.25^{\circ}$ resolution LUH2 dataset into $1-\mathrm{km}$ grids of LULC types that follow the IGBP classification scheme and are consistent with the globally comparable frameworks of SSPs and RCPs. Then, we simulated the spatiotemporal dynamics of global GPP at fiveyear intervals throughout the 21 st century by driving CoLM with this fine resolution global LULC data and different climate forcing. Specifically, we ran multiple CoLM simulations of global GPP for 14 contrasting scenarios of climate forcing and LULC such that the contribution of LULC change to future global GPP dynamics relative to that of climate change could be quantified. The produced 1-km resolution global LULC data over 2015-2100 will be particularly useful for a wide range of land-related sustainability studies $^{23,24}$. Also, the methodology we employed for disentangling the individual impacts of climate and LULC changes on GPP dynamics can be readily applied or easily adapted to study regional or historical GPP dynamics (e.g., You et al. ${ }^{25}$ ), and for decomposing the relative contributions of more GPP-drivers with appropriate process-based GPP simulation models (e.g., Cai \& Prentice ${ }^{26}$; Sun et al. ${ }^{9}$ ). On top of these research opportunities, our results shed timely insights on land monitoring and management imperatives for navigating our human-Earth system toward a more sustainable future.

First and foremost, our results suggest that it will be productive to take land-based actions to build a carbon-neutral world. During 2000-2015, LULC change alone had potentially reduced global GPP by $0.35 \%$, with a mean annual loss of $-0.0379 \mathrm{Pg} \mathrm{C} \mathrm{yr}^{-2}$ (Fig. 3). Given the enormous uncertainty in the estimated trend of GPP dynamics over 1996-2012-ranging from $+0.005 \mathrm{Pg} \mathrm{C} \mathrm{yr}^{-2}$ to $+0.6 \mathrm{Pg} \mathrm{C} \mathrm{yr}^{-}$ ${ }^{2}$ - LULC change would have at least offset the potential increasing trend by $7 \%$. The non-trivial role of 
LULC change in driving global GPP dynamics is further complicated by the considerable uncertainty in the contrasting global LULC change trajectories during 2015-2100 under different SSP-RCP scenarios (Fig. 1). On the one hand, the mean annual global GPP change directly contributed by LULC change could be negligible for 2015-2100 in the two sustainability scenarios; on the other hand, in those unsustainability scenarios, the contribution varies from -0.0303 to $-0.0118 \mathrm{Pg} \mathrm{C} \mathrm{yr}^{-2}$ during 2015-2050 and -0.0408 to $+0.0230 \mathrm{Pg} \mathrm{C} \mathrm{yr}^{-2}$ during 2050-2100 (Fig. 3). Under SSP4-RCP3.4, particularly, LULCchange-induced GPP loss during $2000-2100$ would account for nearly $17 \%$ of the annual carbon sequestration of the Amazon rainforest ${ }^{6}$. More straightforwardly, LULC change contributes to global GPP dynamics by $10.92 \%-16.16 \%$ during $2000-2050$ and $1.41 \%-14.57 \%$ during $2050-2100$ under three representative SSP-RCP scenarios (Table 1). It follows that oversimplifying LULC as static, as currently so practiced in most modeling efforts of global GPP dynamics, would lead to large overestimation of global $\mathrm{GPP}^{27,28}$. Practically, future land management practices and associated socioeconomic development pathways that the global community takes will make a big difference. In other words, from the perspective of carbon-neutrality, the world has no other choice but to transition toward sustainability, including the sustainable use of global land resources 29,30 .

Admittedly, despite LULC change being a non-trivial driver of global GPP dynamics, our results clearly show that its role is generally secondary to climate change (Fig. 8; Table 1). This finding is in line with the conventional view that terrestrial primary productivity is controlled mainly by rising $\mathrm{CO}_{2}$ and changing climate (i.e., temperature, radiation, and precipitation) ${ }^{31}$. According to Cai and Prentice ${ }^{26}$, for the global GPP dynamics during 1982-2016 as simulated by the TRENDY v8 ensemble of state-of-the-art ecosystem models, the contributions of rising $\mathrm{CO}_{2}$ and climate change were $+0.22 \sim 0.52 \mathrm{Pg} \mathrm{C} \mathrm{yr}^{-2}$ and $-0.05 \sim+0.19 \mathrm{Pg} \mathrm{C} \mathrm{yr}^{-2}$, respectively. Relatedly, Sun and colleagues ${ }^{9}$ quantified the relative contributions of rising $\mathrm{CO}_{2}$, climate change, and LULC change to the global GPP dynamics during 1982-2015 based on a C-Fix model, which respectively accounted for $65.73 \%, 17.57 \%$, and $4.57 \%$ - an overall positive contribution of LULC change to the historical GPP increase. This is in contrast to the negative role of LULC change revealed in our study, likely because the world became much greener during $1982-2016^{32}$ while the projected LULC change during 2015-2100 is featured by crop expansion at mainly the cost of grassland and forest losses in most of the unsustainability scenarios (Fig. 1).

Notwithstanding secondary in driving global GPP dynamics, LULC change can be the dominant driver for large areas covering 9,054,884 12,092,465 $\mathrm{km}^{2}$ under different SSP-RCP scenarios-1.65 2.20 times the size of the Amazon rainforest (i.e., 5.50 million $\mathrm{km}^{2}$ ). Historical studies in regional contexts have confirmed the large variations of the LULC change impact on GPP dynamics ${ }^{8,25,33}$. For example, in the middle and lower reaches of the Heihe River Basin in northwestern China, LULC change contributed to as high as $75.1 \%$ of the GPP dynamics during $2001-2016^{25}$. Sun and colleagues ${ }^{9}$ also mapped remarkable global heterogeneity in the contribution of LULC change to GPP dynamics during 1982-2015 in absolute terms instead of relative to climate change. Our study adds to the existing research by mapping at a high resolution the specific locations where LULC-based solutions would be more effective than climate 
mitigation measures in plausible futures. We show that these LULC-change-dominated areas are mainly located at urbanization frontiers in coastal areas and central Africa as well as desert margins, with a relatively stable pattern under three investigated SSP-RCP scenarios (Figs. 8a, b, and c). Such a spatial regularity likely involves the greening of sparsely-vegetated areas due to climate change ${ }^{34}$ or the deforestation at socioeconomic development frontiers ${ }^{35}$, calling for enhanced monitoring and proactive management of such key LULLC change processes in these identified areas.

Notably, the LULC-change-dominated areas identified in this study differ from those GPP-rich biomes/regions (e.g., the Amazon rainforest), a popular research focus and emphasis (e.g., Qin et al. ${ }^{36}$; Sun et al. $\left.{ }^{9}\right)$. We singled out five such GPP-rich areas-Eastern North America, Central South America, Europe, Central Africa, and East and Southeast Asia, which are also the main GPP change hotspots - for separate and comparative analysis of LULC change impacts on future GPP dynamics. Our results show that, although these areas would experience GPP loss of varying degrees in most of the eight LULCchange-driven scenarios, they share no similar GPP change trajectories. Instead, their future GPP dynamics would be strongly dependent on LULC change trajectories and the corresponding SSP-RCP scenarios (Fig. 5). Furthermore, under SSP2-RCP4.5, SSP4-RCP6.0, and SSP5-RCP8.5 with the combined impacts of future climate and LULC changes, the relative contribution of LULC change to the global GPP dynamics would be larger during 2000-2050 than 2050-2100. This temporal pattern is opposite from that of the five GPP-rich areas (Fig. 5). These two observations suggest that LULC change monitoring and management in GPP-rich areas alone is not enough.

From a temporal perspective, our results seem to indicate that the year 2050 is a critical tipping point in terms of future LULC change (Fig. 1), LULC change impacts on global and key regional GPP dynamics (Figs. 3 and 5), and the relative contributions of future climate and LULC changes (Fig. 6 and Table 1). Given that other studies such as Chen et al. ${ }^{37}$ also identified tipping points in the mid-twenty-first century, we believe this is a reasonable speculation. Notwithstanding that it is largely speculative, this temporal observation implies potentially a narrow window for timely sustainability interventions. From a complex adaptive human-Earth system perspective, long-term social-environmental trends such as the LULC and GPP change trajectories (2000-2100) depicted in this study result from intrinsic self-reinforcing feedback loops that make the system path-dependent and often irreversible $38,39,40$. If the year 2050 is indeed such a critical point, then the time window for taking proactive LULC-based actions to build a carbon-neutral world is quickly vanishing; the global community must act now and together.

To the best of our knowledge, our study is the first of its kind to quantify future LULC change impact on global GPP dynamics throughout the 21 st century considering relatively comprehensive SSP-RCP scenario settings and at a relatively high 1-km resolution. Quesada et al. ${ }^{41}$ made a similar effort to assess the comprehensive impacts of LULC change on seven key variables characterizing the terrestrial carbon cycle, focusing on 2070-2100 and considering mainly the business-as-usual RCP8.5 scenario. Given the complexity of the human-Earth system, the uncertainty of future LULC change, and the unsatisfying understanding of the terrestrial carbon cycle, much more research is needed. Although our 
findings provide timely heuristic insights into land monitoring and management imperatives, our study includes a few limitations which can open new doors for the following research steps. First, we used only one model for GPP simulations, unable to capture the uncertainty introduced by model diversity 7,26 . Second, we excluded the impacts of other GPP-drivers (e.g., rising $\mathrm{CO}_{2}$ and anthropogenic nitrogen inputs) from our modeling to focus our analysis on the roles of LULC change versus climate change, providing an incomplete assessment of their relative contributions ${ }^{9,31}$. In addition, we considered only GPP dynamics, not considering the full terrestrial carbon cycle ${ }^{41}$. With the increasing availability of future LULC datasets as shared here, our study can serve as a first step to motivate future research in this area toward a better understanding of the terrestrial carbon cycle in a highly uncertain future with both natural and anthropogenic changes. Further still, linking these future LULC maps with other integrated assessment models will facilitate a deeper understanding of the multi-dimensional social-environmental impacts of future LULC change, and help decision-makers navigate our human-Earth system through uncertainties toward a more sustainable future.

\section{Methods}

Research Design. To disentangle the relative contributions of climate and LULC changes to global GPP dynamics, we designed three sets of numerical experiments simulating global GPP dynamics over 20002100 under scenarios driven by (I) LULC change and constant climate, (II) climate change and constant LULC, and (III) both climate and LULC changes. Following Wu and colleagues (2014) ${ }^{42}$, the GPP difference between the I-set and III-set of experiments can be attributed to the contribution of climate change ( $\triangle$ Clim.GPP). Similarly, the GPP difference of the II-set and III-set of experiments can determine the contribution of LULC change ( $\triangle$ LULC.GPP), while the contribution of all other factors can be measured as the GPP difference between the III-set of experiments and the sum of I- and II-sets of experiments ( $\triangle$ Residual.GPP). Accordingly, the relative contributions of climate change (Contr.Clim), LULC change (Contr.LULC), and changes in other factors (Contr.Res) to global GPP dynamics can be quantified using the following three equations:

$$
\begin{aligned}
& \text { Contr. Clim }=\frac{\mid \Delta \text { Clim.GPP } \mid}{|\Delta L U L C . G P P|+\mid \Delta \text { Clim.GPP }|+| \Delta \text { ResiduaL.GPP } \mid} \times 100 \% \\
& \text { Contr. LULC }=\frac{|\Delta L U L C . G P P|}{|\Delta L U L C, G P P|+|\Delta C l i m . G P P|+\mid \Delta R \text { Residual.GPP } \mid} \times 100 \%
\end{aligned}
$$$$
\text { Contr. } \text { Res }=100 \%-\text { Contr. LULC }- \text { Contr. Clim }
$$

To put the above contribution decomposition into a context of plausible futures, we conducted the I-set of eight experiments by only changing LULC, with LULC inputs produced under the coupled scenarios of SSP1-RCP1.9, SSP1-RCP2.6, SSP4-RCP3.4, SSP5-RCP3.4, SSP2-RCP4.5, SSP4-RCP6.0, SSP3-RCP7.0, and SSP5-RCP8.5 (see below for details). For the II-set of experiments that change only the climate inputs, we used three open datasets consistent with RCP4.5, RCP6.0, and RCP8.5 derived from the Community Earth System Model 4 (CESM; Supplementary Table 1). Note that climate forcing consistent with the RCP1.9, 
RCP2.6, RCP3.4, and RCP7.0 scenarios was not included due to the lack of available data. Further, we conducted the III-set of three experiments, i.e., Clim45-LULC245, Clim60-LULC460, and Clim85-LULC585, using the three matched LULC and climate datasets. In total, we conducted 14 computationally intensive experiments (Supplementary Table 1).

Global GPP simulation by CoLM. To simulate the global GPP in the 14 computational experiments, we used the $\mathrm{CoLM}^{22}$, a widely-used process-based model for estimating carbon, water, and energy fluxes at regional and global scales ${ }^{43,44,45,46}$. Initially, the CoLM was adopted as the Community Land Model (CLM), with the integration of three well-known LSMs-the National Center for Atmospheric Research (NCAR) LSM ${ }^{47}$, the biosphere-atmosphere transfer scheme (BATS) ${ }^{48}$, and the Chinese Academy of Sciences Institute of Atmospheric Physics LSM (IAP94) ${ }^{49}$. In the latest version of CoLM 2014, several key improvements were implemented, such as the updated calculation of soil parameters and a two-big-leaf scheme for photosynthesis and stomatal resistance ${ }^{50,51}$.

Since it considers various biogeochemical, biogeophysical, and hydrological processes between the landatmosphere interface, the CoLM can capture key parameters such as soil moisture, sensible, latent heat fluxes, and canopy assimilation rate of photosynthesis (i.e., GPP) ${ }^{22}$. Worldwide comprehensive validation has shown that the CoLM has competent performance in simulating GPP dynamics at the global scale ${ }^{52,53}$ (see also Supplementary Fig. 7). To drive CoLM, climate forcing (e.g., precipitation, temperature, radiation, humidity) and land surface background (e.g., LULC, LAl, soil property, topography) are needed. Specifically, we used the average of Climate Research Unit-National Centers for Environmental Prediction (CRUNCEP) dataset from 1990 to 2017 as the constant climate forcing input in the l-set of eight experiments, and used the historical LULC data of 2001 as the constant LULC input in the II-set of three experiments. The future climate forcing data consistent with RCPs were obtained from the CESM 4, as noted above. The historical and projected climate data are $0.5^{\circ}$, and the historical LULC data are $1-\mathrm{km}$ resolution. Thus, the future LULC data consistent with SSPs and RCPs were produced by downscaling the LUH2 dataset to 1 -km grids at 5-year intervals throughout the 21 st century.

Downscaling LUH2 dataset to 1-km LULC grids by FLUS. The LUH2 datasets include LULC under the abovementioned eight SSP-RCP scenarios for every $0.25^{\circ}$ grid throughout the $21 \mathrm{st}$ century. Yet two issues hinder the direct application of the LUH2 datasets to drive CoLM. One is that its classification scheme of 13 LULC types (including forested primary land, non-forested primary land, forested secondary land, nonforested secondary land, pasture, rangeland, urban, C3 annual crops, C3 perennial crops, C4 annual crops, C4 perennial crops, C3 nitrogen-fixing crops, and water/ice, see http://luh.umd.edu for details) does not match the IGBP classification scheme of 17 LULC types as required by CoLM. To convert the LUH2 datasets into the IGBP-consistent format, we first mapped the LUH2 LULC types into six broad categories, i.e., forest, grassland, agriculture, urban, barren, and ice/water (see Supplementary Table 2 for mapping rules). The data of these six broad categories were then mapped into the IGBP LULC types, based on the simplification that the proportion of each IGBP class within each of the six broad categories is temporally invariant in a socioeconomic region ${ }^{54,55,56}$. Specifically, we multiplied the amounts of the six broad LULC 
categories with the mean fraction of the IGBP-consistent MODIS LULC data from 2001 to 2016. In doing so, the future amounts of the 17 IGBP LULC types under the eight SSP-RCP scenarios were obtained for every socioeconomic region throughout the 21 st century.

The other issue is that the $0.25^{\circ}$ resolution of the LUH2-converted LULC data does not match the $1-\mathrm{km}$ fine resolution of other CoLM inputs. To do the downscaling, we used an advanced LULC change simulation model called FLUS to simulate global LULC patterns based on disaggregated simulations of 26 world socioeconomic regions (Supplementary Fig. 8, as defined in the 5th Intergovernmental Panel on Climate Change Assessment Report (IPCC AR5) of Managing the Risks of Extreme Events and Disasters to Advance Climate Change Adaptation (SREX)). These FLUS simulations involved two general steps. The first step was to estimate the probability of occurrence of each LULC type at each grid. This was done in FLUS by Artificial Neutral Network algorithms that capture the nonlinear relationships between potential social-environmental drivers and the initial LULC patterns of each of the 26 regions in 2015. The initial LULC patterns were derived from the 2015 MODIS Land Cover Product (MCD12Q1 v006). Previous studies have found that LULC patterns are influenced by various factors such as climate change and human policies mainly driven by the economic demand ${ }^{57,58}$. In our FLUS simulations, we included socioeconomic development and locational factors (GDP, population, and location of the target land cell), topographic conditions (elevation and slope), and the climate and soil status (temperature, precipitation, and soil texture) as the potential drivers (Supplementary Table 3). The second step was to allocate the most likely LULC type to each grid based on the initial MODIS LULC pattern in 2015 and the constraint of the future amount of each LULC type at a specific year. The spatial allocation followed a so-called selfadaptive inertia and competition mechanism $\mathrm{CA}^{14}$. Note that the amount of each LULC type in 2015 in the MODIS Land Cover Product does not match that in the LUH2-converted dataset. To maintain consistency, we further calibrated the future LULC amount constraints from the LUH2 converted datasets to match the 2015 MODIS dataset. Specifically, the future amount of each LULC type was determined by multiplying its area in the 2015 MODIS dataset with the relative change from its area in 2015 to its projected area at the future year based on the LUH2-converted datasets (i.e., the relative change for each LULC was calculated as future LUH2-converted area divided by 2015 LUH2-converted area). The calibrated LULC datasets were used for illustration in Fig. 1 and for constraining the FLUS simulations. The validation of FLUS model is shown in Supplementary Table 4. For more details about FLUS and its improvements over similar CA-based LULC simulation models, please refer to Li et al. ${ }^{14}$, Liang et al. ${ }^{59}$, and Liu et al. ${ }^{60}$.

\section{Data availability}

The LUH2 dataset used to project future LULC in this study is available at https://luh.umd.edu/. The MODIS land cover product is available at https://lpdaac.usgs.gov/products/mcd12q1v006/. The historical climate dataset of CRUNCEP v7 is available at https://rda.ucar.edu/datasets/ds314.3/. The future climate forcing data for driving CoLM is available 
at https://www.cesm.ucar.edu/models/cesm1.0/clm/clm_ccsm4forcingdata_esg.html. To download the LULC data produced in this study - the 1-km resolution global LULC data covering 2015-2100 at five-year intervals that follow the IGBP classification scheme and are consistent with SSP-RCPs- please refer to http://www.geosimulation.cn/.

\section{Code availability}

The FLUS model developed by Dr. Xia Li and colleagues for LULC simulation and optimization is freely accessible at http://www.geosimulation.cn/. The CoLM developed by Dr. Yongjiu Dai and colleagues for simulating land surface processes (e.g., GPP) is freely available at http://globalchange.bnu.edu.cn/.

\section{References}

1. Le Quere C, et al. Global Carbon Budget 2018. Earth Syst Sci Data 10, 2141-2194 (2018).

2. Zhang $Y$, et al. On the relationship between sub-daily instantaneous and daily total gross primary production: Implications for interpreting satellite-based SIF retrievals. Remote Sens Environ 205, 276-289 (2018).

3. Beer C, et al. Terrestrial Gross Carbon Dioxide Uptake: Global Distribution and Covariation with Climate. Science 329, 834-838 (2010).

4. Erb KH, et al. Analyzing the global human appropriation of net primary production - processes, trajectories, implications. An introduction. Ecol Econ 69, 250-259 (2009).

5. Reichstein M, et al. Climate extremes and the carbon cycle. Nature 500, 287-295 (2013).

6. Zhao MS, Heinsch FA, Nemani RR, Running SW. Improvements of the MODIS terrestrial gross and net primary production global data set. Remote Sens Environ 95, 164-176 (2005).

7. Anav A, et al. Spatiotemporal patterns of terrestrial gross primary production: A review. Rev Geophys 53, 785-818 (2015).

8. Jia $\mathrm{BH}$, et al. Impacts of land use change and elevated $\mathrm{CO} 2$ on the interannual variations and seasonal cycles of gross primary productivity in China. Earth Syst Dynam 11, 235-249 (2020).

9. Sun ZY, et al. Spatial pattern of GPP variations in terrestrial ecosystems and its drivers: Climatic factors, CO2 concentration and land-cover change, 1982-2015. Ecol Inform 46, 156-165 (2018).

10. Zhang YL, Song CH, Band LE, Sun G. No Proportional Increase of Terrestrial Gross Carbon Sequestration From the Greening Earth. J Geophys Res-Biogeo 124, 2540-2553 (2019).

11. Houghton RA, Nassikas AA. Global and regional fluxes of carbon from land use and land cover change 1850-2015. Global Biogeochem Cy 31, 456-472 (2017).

12. Madani $\mathrm{N}$, et al. Improving ecosystem productivity modeling through spatially explicit estimation of optimal light use efficiency. J Geophys Res-Biogeo 119, 1755-1769 (2014). 
13. Lawrence DM, et al. The Land Use Model Intercomparison Project (LUMIP) contribution to CMIP6: rationale and experimental design. Geosci Model Dev 9, 2973-2998 (2016).

14. Li X, et al. A New Global Land-Use and Land-Cover Change Product at a 1-km Resolution for 2010 to 2100 Based on Human-Environment Interactions. Annals of the American Association of Geographers 107, 1040-1059 (2017).

15. Sohl TL, et al. A land-use and land-cover modeling strategy to support a national assessment of carbon stocks and fluxes. Applied Geography 34, 111-124 (2012).

16. Hurtt GC, et al. Harmonization of Global Land-Use Change and Management for the Period 8502100 (LUH2) for CMIP6. Geosci Model Dev (2020).

17. Moss $\mathrm{RH}$, et al. The next generation of scenarios for climate change research and assessment. Nature 463, 747-756 (2010).

18. O'Neill BC, et al. A new scenario framework for climate change research: the concept of shared socioeconomic pathways. Climatic Change 122, 387-400 (2013).

19. Yu Z, Lu C, Tian H, Canadell JG. Largely underestimated carbon emission from land use and land cover change in the conterminous United States. Glob Chang Biol 25, 3741-3752 (2019).

20. Chen $\mathrm{M}$, et al. Global land use for $2015-2100$ at $0.05^{\circ}$ resolution under diverse socioeconomic and climate scenarios. Sci Data 7, 320 (2020).

21. Liao WL, et al. Projections of land use changes under the plant functional type classification in different SSP-RCP scenarios in China. Sci Bull 65, 1935-1947 (2020).

22. Dai Y, et al. The Common Land Model. Bulletin of the American Meteorological Society 84, 10131024 (2003).

23. National Research Council. Our Common Journey: A Transition Toward Sustainability. The National Academies Press (1999).

24. Turner $\mathrm{BL}$, Lambin EF, Reenberg $\mathrm{A}$. The emergence of land change science for global environmental change and sustainability. P Natl Acad Sci USA 104, 20666-20671 (2007).

25. You NS, et al. Isolating the Impacts of Land Use/Cover Change and Climate Change on the GPP in the Heihe River Basin of China. J Geophys Res-Biogeo 125 (2020).

26. Cai WJ, Prentice IC. Recent trends in gross primary production and their drivers: analysis and modelling at flux-site and global scales. Environ Res Lett 15, (2020).

27. Huntzinger DN, et al. The North American Carbon Program Multi-Scale Synthesis and Terrestrial Model Intercomparison Project - Part 1: Overview and experimental design. Geosci Model Dev 6, 2121-2133 (2013).

28. Lawrence PJ, Lawrence DM, Hurtt GCJJoGRB. Attributing the carbon cycle impacts of CMIP5 historical and future land use and land cover change in the Community Earth System Model (CESM1). 123, 1732-1755 (2018).

29. Wu JG. Landscape sustainability science: ecosystem services and human well-being in changing landscapes. Landscape Eco/ 28, 999-1023 (2013). 
30. Verburg PH, et al. Land system science and sustainable development of the earth system: A global land project perspective. Anthropocene 12, 29-41 (2015).

31. Pan SF, et al. Modeling and Monitoring Terrestrial Primary Production in a Changing Global Environment: Toward a Multiscale Synthesis of Observation and Simulation. Adv Meteorol 2014 (2014).

32. Song XP, et al. Global land change from 1982 to 2016. Nature 560, 639-+ (2018).

33. Luo X, Jia B, Lai X. Contributions of climate change, land use change and $\mathrm{CO} 2$ to changes in the gross primary productivity of the Tibetan Plateau. Atmospheric and Oceanic Science Letters 13, 8$15(2020)$.

34. Chen C, et al. China and India lead in greening of the world through land-use management. Nat Sustain 2, 122-129 (2019).

35. Seto KC, Guneralp B, Hutyra LR. Global forecasts of urban expansion to 2030 and direct impacts on biodiversity and carbon pools. P Natl Acad Sci USA 109, 16083-16088 (2012).

36. Qin YW, et al. Carbon loss from forest degradation exceeds that from deforestation in the Brazilian Amazon. Nat Clim Change 11, 442-+ (2021).

37. Chen GZ, et al. Global projections of future urban land expansion under shared socioeconomic pathways. Nat Commun 11 (2020).

38. Turner B, Clark WC, Kates RW, Richards JF, Mathews JT, Meyer WB. The Earth as transformed by human action. In: global change and regional changes in the biosphere over the past 300 years). Cambridge University Press, with Clark University (1990).

39. Kates RW, et al. Environment and development - Sustainability science. Science 292, 641-642 (2001).

40. Levin S, Clark W. Toward a Science of Sustainability: Report from Toward a Science of Sustainability Conference; Airlie Center Warrenton, Virginia.) (2010).

41. Quesada B, Arneth A, Robertson E, de Noblet-Ducoudre N. Potential strong contribution of future anthropogenic land-use and land-cover change to the terrestrial carbon cycle. Environ Res Lett 13 (2018).

42. Wu SH, Zhou SL, Chen DX, Wei ZQ, Dai L, Li XG. Determining the contributions of urbanisation and climate change to NPP variations over the last decade in the Yangtze River Delta, China. Sci Total Environ 472, 397-406 (2014).

43. Jiafu M, Li D, Bin W, Yongjiu D. Simulation and evaluation of terrestrial ecosystem NPP with MSDGVM over continental China. ADVANCES IN ATMOSPHERIC SCIENCES 27, 427-441 (2010).

44. Ji D, et al. Description and basic evaluation of Beijing Normal University Earth System Model (BNUESM) version 1. Geosci Model Dev 7, 2039-2064 (2014).

45. Zhang XX, et al. Evaluating common land model energy fluxes using FLUXNET data. Advances in Atmospheric Sciences 34, 1035-1046 (2017). 
46. Huang CL, Li X, Lu L. Retrieving soil temperature profile by assimilating MODIS LST products with ensemble Kalman filter. Remote Sens Environ 112, 1320-1336 (2008).

47. Bonan GB, et al. The land surface climatology of the community land model coupled to the NCAR community climate model. J Climate 15, 3123-3149 (2002).

48. Dickinson RE, Henderson-Sellers A, Kennedy PJ. Biosphere-atmosphere Transfer Scheme (BATS) Version 1e as Coupled to the NCAR Community Climate Model. John Wiley \& Sons, Ltd (1993).

49. Dai YJ, Zeng QC. A land surface model (IAP94) for climate studies. Part I: Formulation and validation in off-line experiments. Adv Atmos Sci 14, 433-460 (1997).

50. Li C, et al. Evaluation of the Common Land Model (CoLM) from the Perspective of Water and Energy Budget Simulation: Towards Inclusion in CMIP6. Atmosphere 8 (2017).

51. Dai YJ, Dickinson RE, Wang YP. A two-big-leaf model for canopy temperature, photosynthesis, and stomatal conductance. J Climate 17, 2281-2299 (2004).

52. Tramontana G, et al. Predicting carbon dioxide and energy fluxes across global FLUXNET sites with regression algorithms. Biogeosciences 13, 4291-4313 (2016).

53. Jung $\mathrm{M}$, et al. Compensatory water effects link yearly global land $\mathrm{CO} 2$ sink changes to temperature. Nature 541, 516-520 (2017).

54. Dong N, You L, Cai WJ, Li G, Lin H. Land use projections in China under global socioeconomic and emission scenarios: Utilizing a scenario-based land-use change assessment framework. Global Environ Chang 50, 164-177 (2018).

55. Ghimire B, et al. Global albedo change and radiative cooling from anthropogenic land cover change, 1700 to 2005 based on MODIS, land use harmonization, radiative kernels, and reanalysis. Geophysical Research Letters 41, 9087-9096 (2014).

56. Gao F, et al. Multiscale climatological albedo look-up maps derived from moderate resolution imaging spectroradiometer BRDF/albedo products. Journal of Applied Remote Sensing 8 (2014).

57. Lambin EF, et al. The causes of land-use and land-cover change: moving beyond the myths. Global Environ Chang 11, 261-269 (2001).

58. Strengers B, Leemans R, Eickhout B, de Vries B, Bouwman L. The land-use projections and resulting emissions in the IPCC SRES scenarios scenarios as simulated by the IMAGE 2.2 model. GeoJournal 61, 381-393 (2004).

59. Liang X, Liu X, Li X, Chen Y, Tian H, Yao Y. Delineating multi-scenario urban growth boundaries with a CA-based FLUS model and morphological method. Landscape and Urban Planning 177, 47-63 (2018).

60. Liu X, et al. A future land use simulation model (FLUS) for simulating multiple land use scenarios by coupling human and natural effects. Landscape and Urban Planning 168, 94-116 (2017).

\section{Declarations}

\section{Acknowledgements}


This study was supported by the Key National Natural Science Foundation of China (Grant No. 4213000279), Academic Innovation Promotion Program for Excellent Doctoral Students of East China Normal University (Grant No. YBNLTS2019-004). We thank China Scholarship Council (CSC) for the financial support. We thank Prof. Hua Yuan \& Prof. Yongjiu Dai from Sun Yat-sen University for providing help of running of CoLM. We thank Guangzhao Chen from the Chinese University of Hong Kong for providing technical help.

\section{Author contributions}

H.H. and B.Z. contributed equally to this work; X.L., F.P. and H.H. conceived the research and planed the analysis. H.H. and G.H. performed experiments and computational analysis. H.H. and B.Z. drafted the manuscript. G.H., F.P., X.L, Z.S., Y.Z. and H.Z. revised the manuscript. Y.G. and M.L. provided technical and data support.

\section{Competing interests}

The authors declare no competing interests.

\section{Figures}


Global Future LULC driven by FLUS
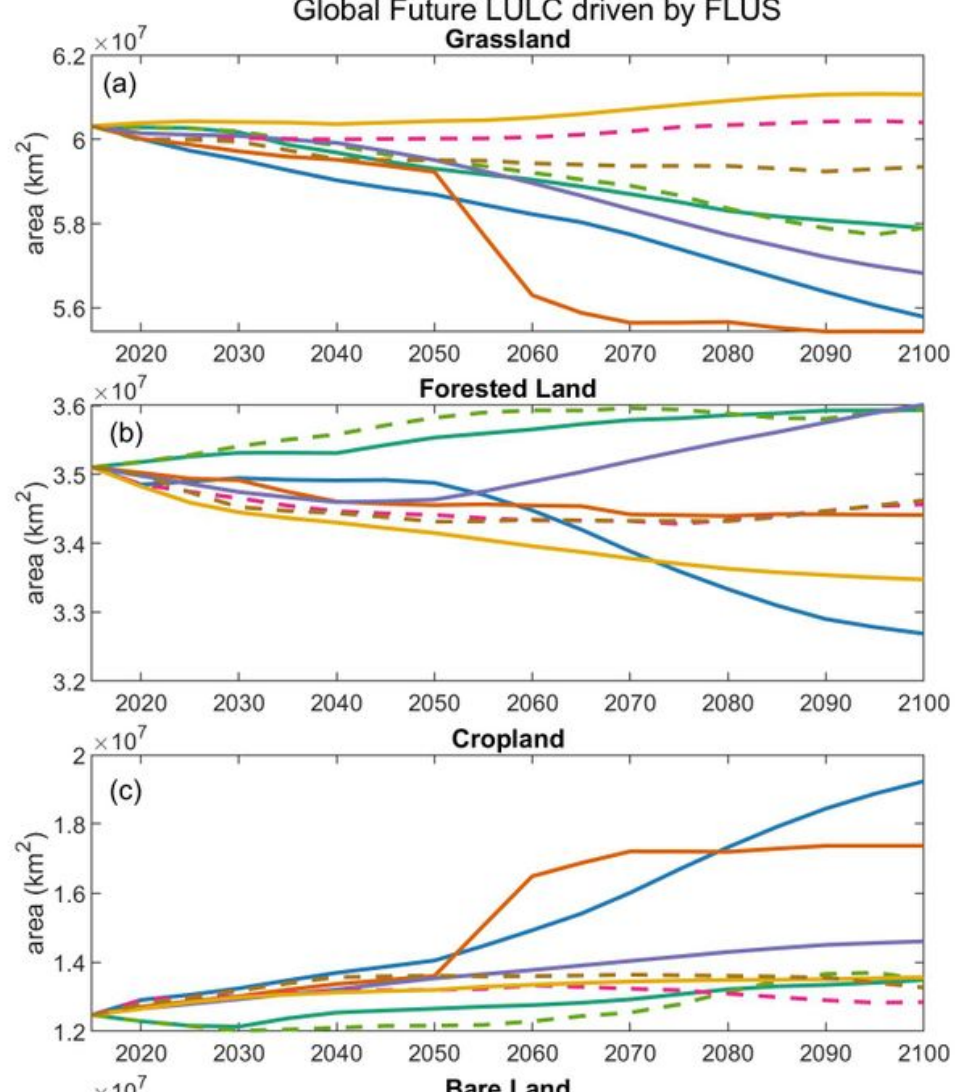

Bare Land
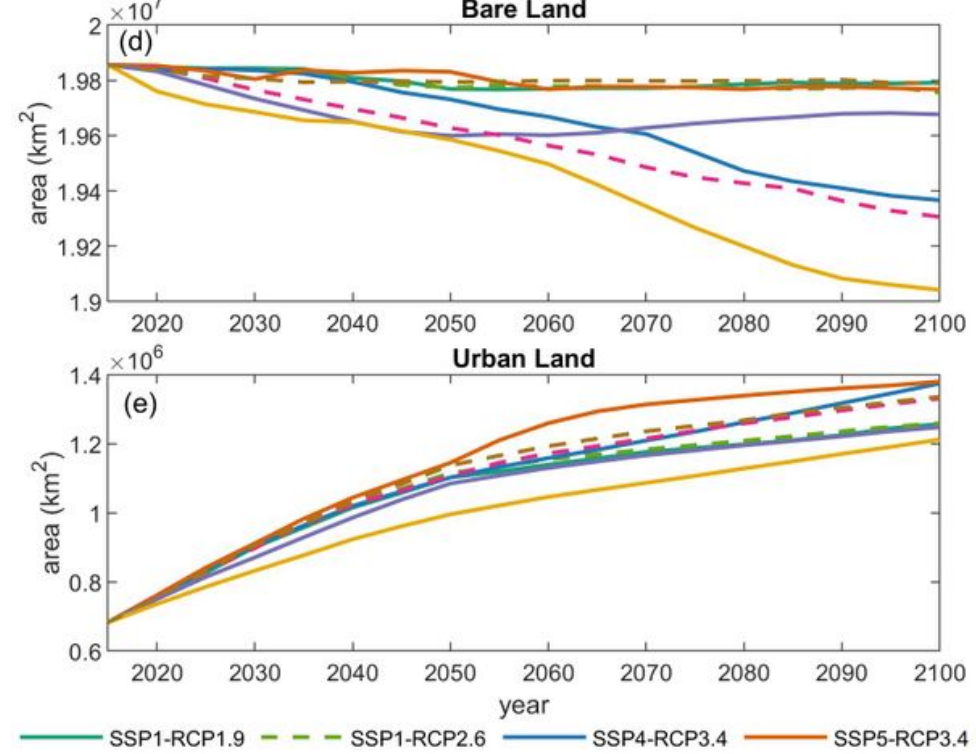

Global Future LULC from LUH2
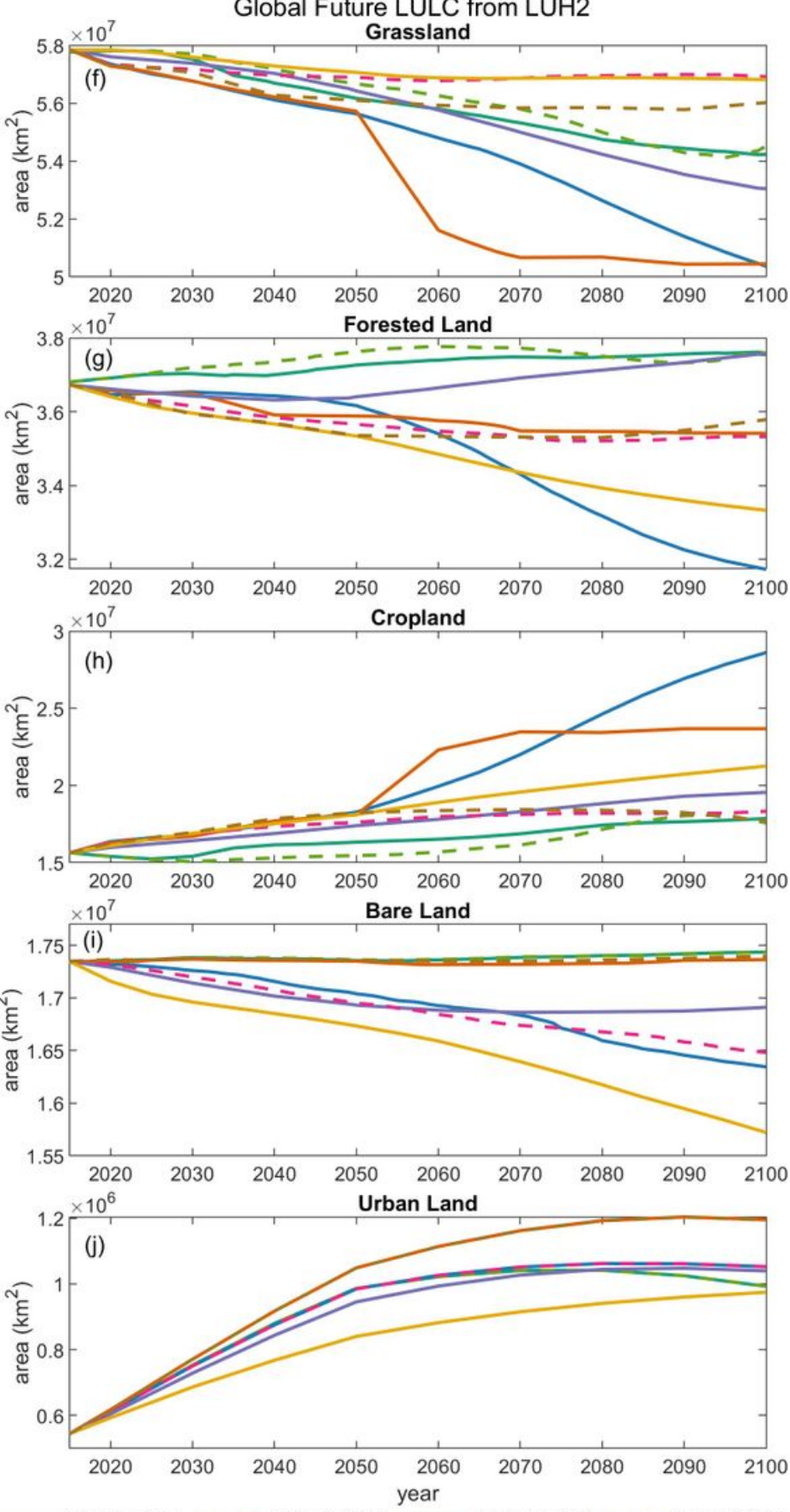

Figure 1

Global LULC changes over the 21st century under eight SSP-RCP scenarios, projected in this study (a-e) versus the LUH2 project (f-j). The five Shared Socioeconomic Pathway (SSP) settings represent the corresponding scenarios of sustainability (SSP1), middle of the road (SSP2), regional rivalry (SSP3), inequality (SSP4), and fossil-fueled development (SSP5). The seven Representative Concentration Pathway (RCP) settings stand for different pathways of global $\mathrm{CO} 2$ emissions as indicated by the corresponding numbers of radiative forcing in the unit of $\mathrm{W} / \mathrm{m} 2$. The LULC types are grouped into six broad categories based on the second-level classification of the IGBP scheme. 

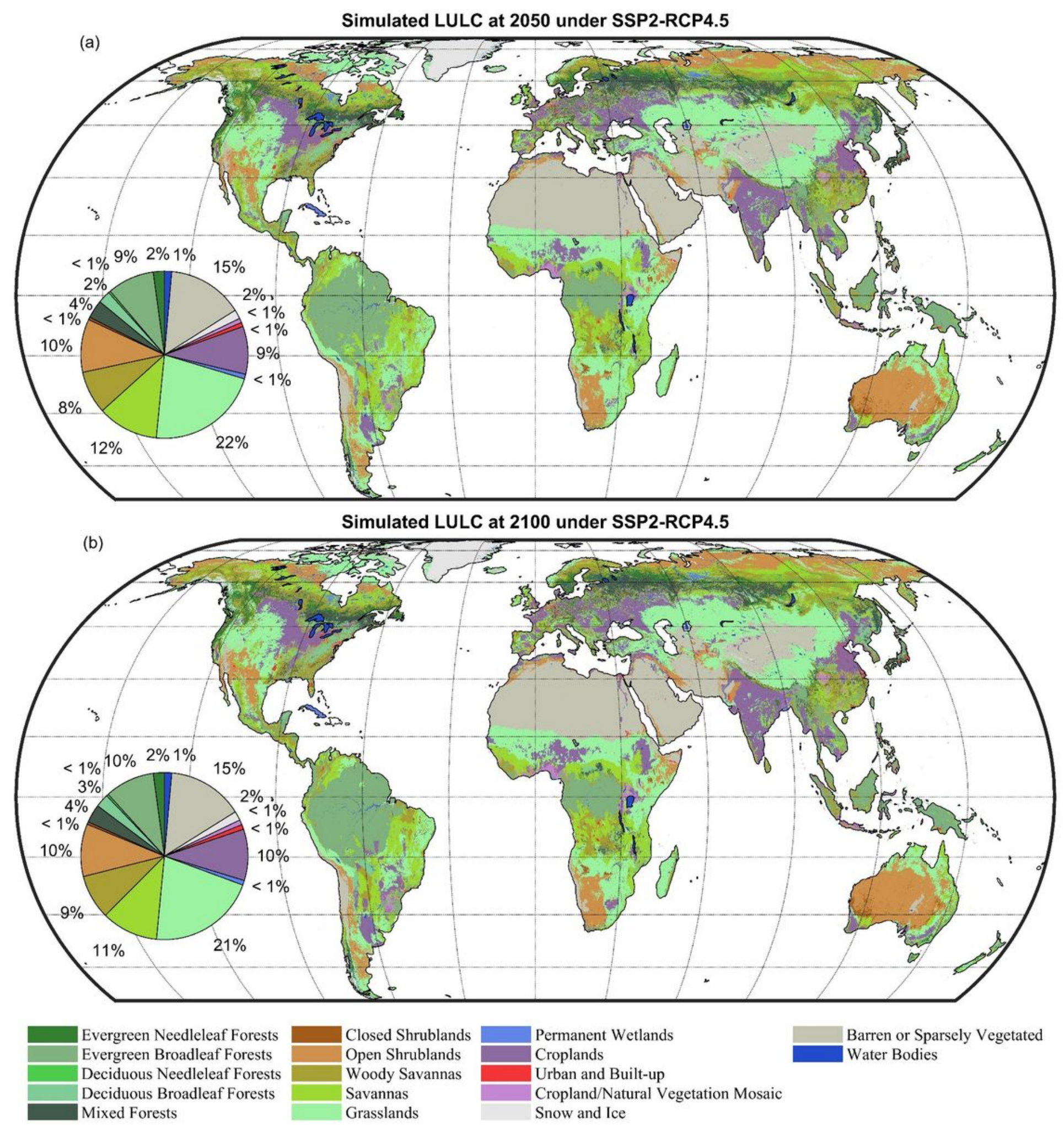

\section{Figure 2}

Simulated global LULC at 2050 (a) and 2100 (b) in the middle of the road scenario (SSP2-RCP4.5). At the lower-left bottom, the two pie figures show the corresponding global LULC structures at 2050 and 2100. The LULC types follow the second-level classification of the IGBP scheme. The spatial pattern change is barely noticeable at the global scale, yet the structural changes of the global land system are featured by 
the increases of evergreen broadleaf forests, deciduous needleleaf forests, woody savannas, and croplands accompanied by the decreases of savannas and grasslands.

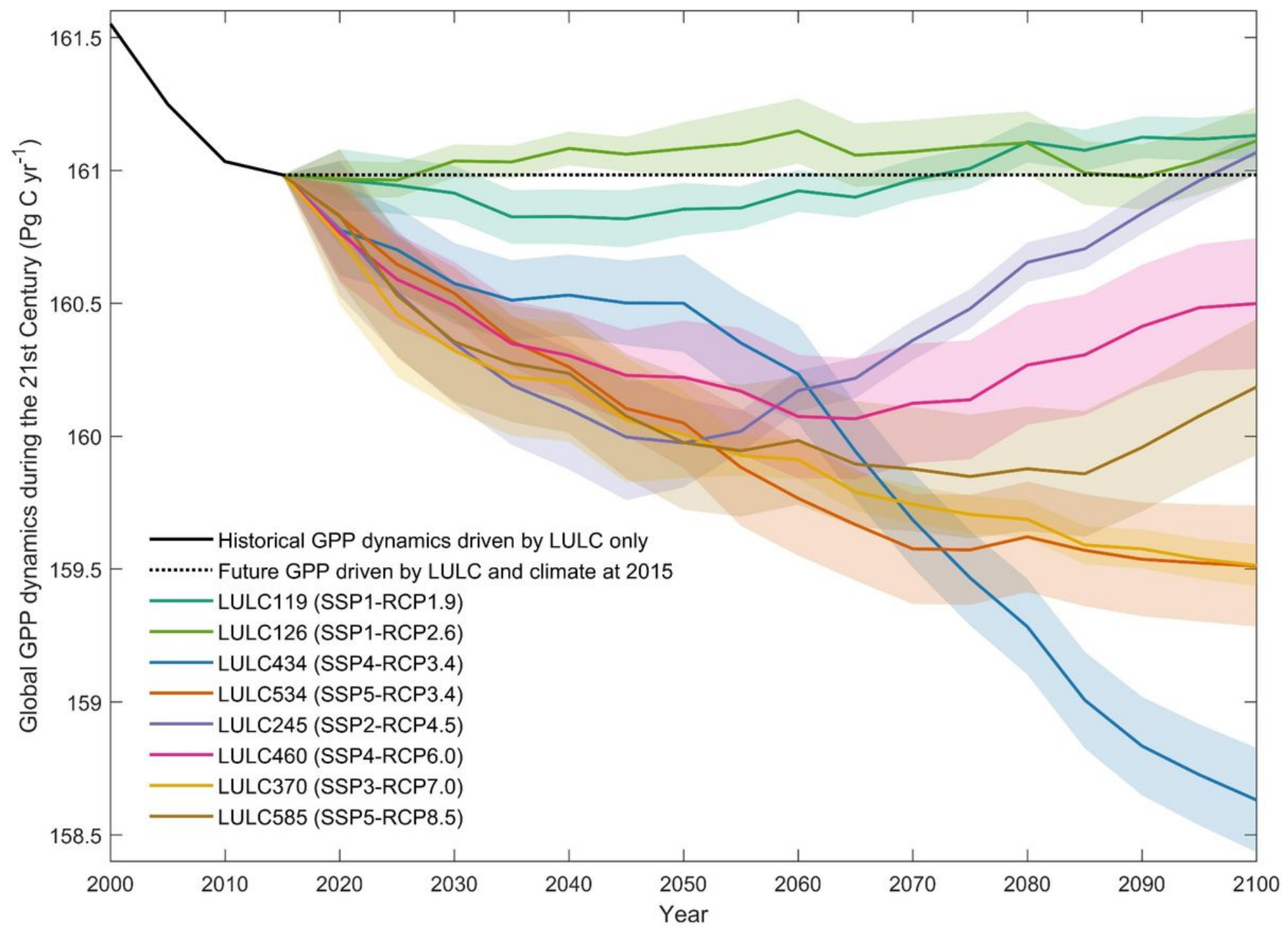

\section{Figure 3}

Global trends of GPP dynamics throughout the 21st century, simulated by only changing the LULC input in CoLM. The shaded areas represent the 95\% confidence intervals of the projected GPP over 2015-2100. The projected GPP trend is strongly affected by future LULC changes, with remarkable uncertainties during 2050-2100 under different SSP-RCP scenarios. Note that the global trend of GPP dynamics would remain largely stable when driven by LULC changes in the two sustainability scenarios (i.e., SSP1-RCP1.9 and SSP1-RCP2.6). 

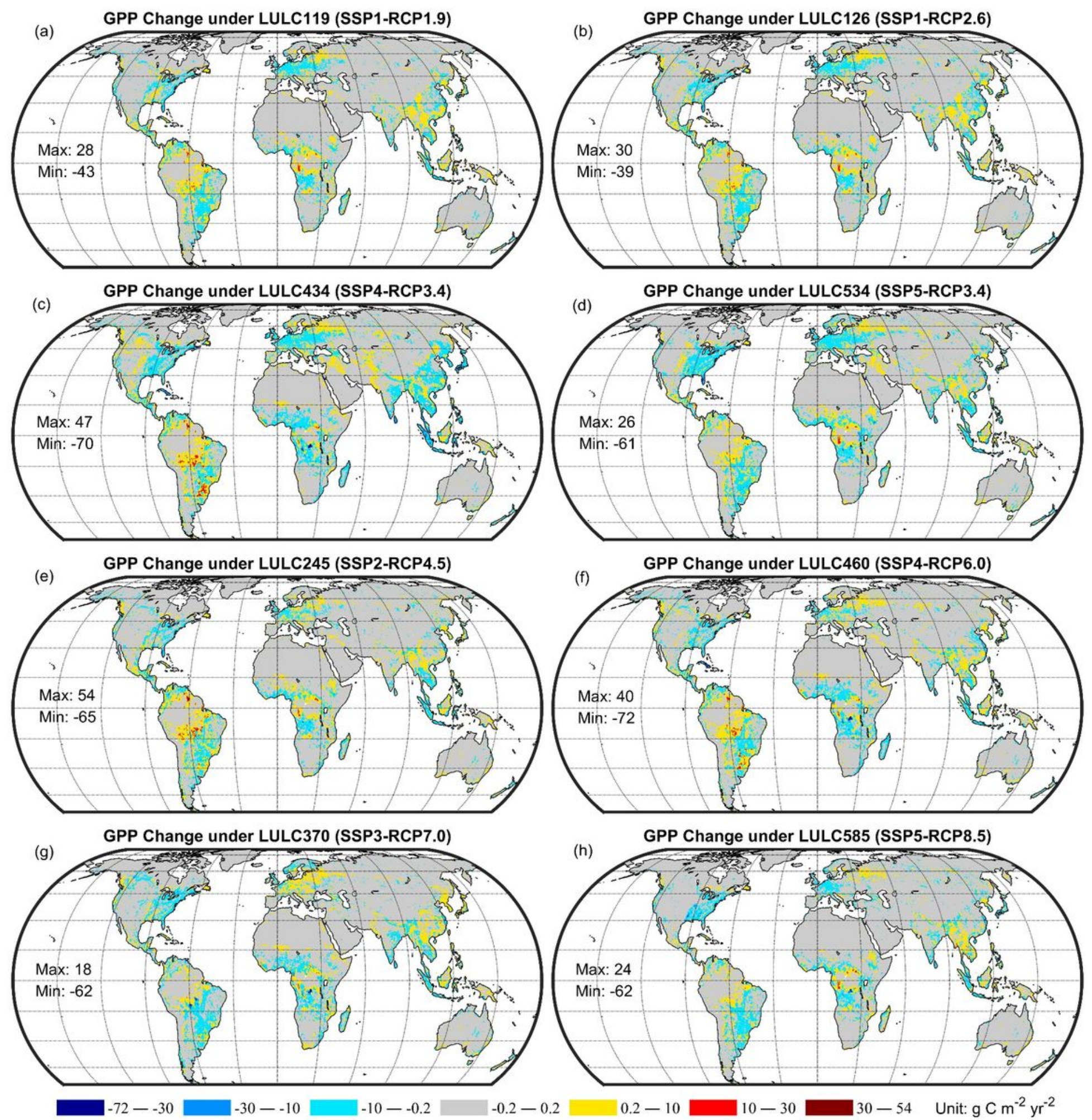

Figure 4

Global patterns of annual GPP change during 2015-2100 under eight future LULC scenarios. a LULC119, b LULC126, c LULC434, d LULC534, e LULC245, f LULC460, g LULC370, h LULC585. The annual GPP change for each grid is computed based on the Sen's slope of the 18 GPP projections for every five years from 2015 to 2100 . Though the majority of the world would experience minor GPP changes (i.e., gray 
areas) in all the LULC scenarios, there are noticeable regional variations among the areas of significant GPP changes (e.g., blue and red areas).

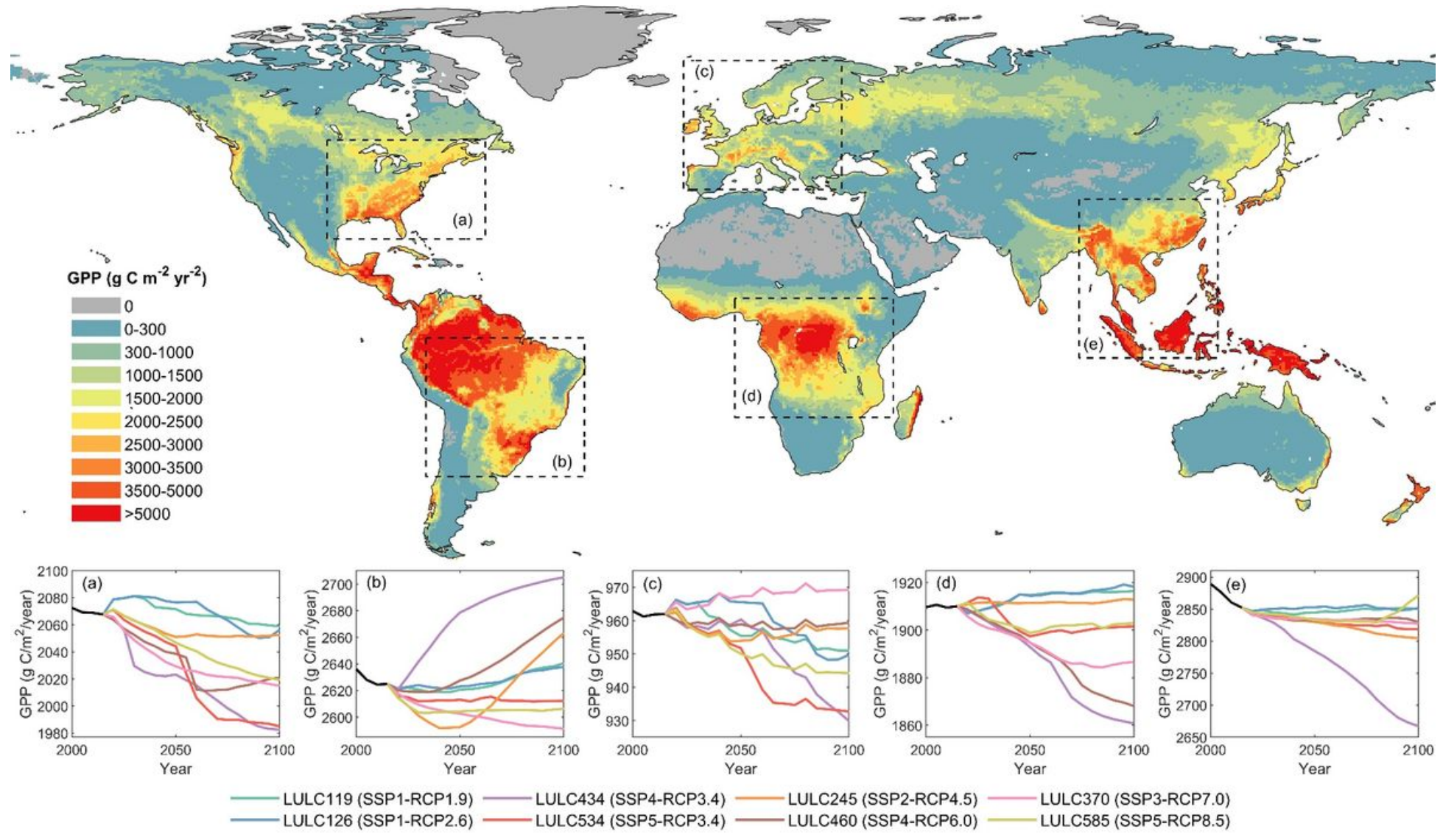

\section{Figure 5}

Simulated historical and future trends of GPP change hotspots under the eight SSP-RCP scenarios for 2000-2100. a East North America, b Central South America, c Europe, d Central Africa, e East and Southeast Asia. The hotspots are identified visually from Fig. 3. All the results are based on CoLM simulations driven by different LULC inputs. Notably, the five hotspot areas would experience GPP loss of varying degrees in most of the scenarios. 


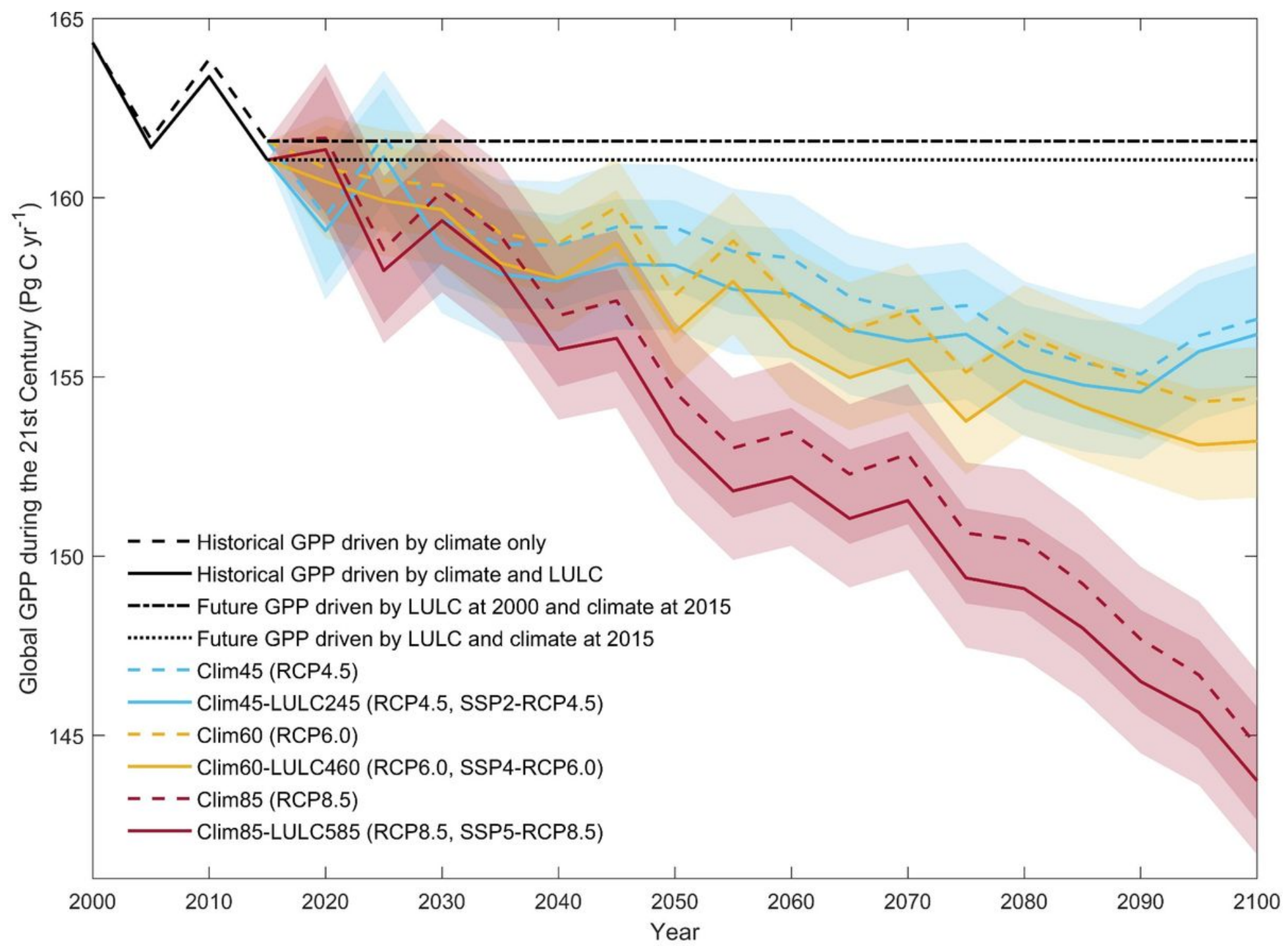

Figure 6

Global trends of GPP dynamics throughout the 21 st century, simulated by only changing the climate input in CoLM (solid lines) and by changing both the climate and LULC inputs (dashed lines). The shaded areas represent the $95 \%$ confidence intervals of the projected GPP over 2015-2100. The contrasting GPP trends under different RCPs, together with the similar trends under RCPs and the corresponding SSPRCPs, suggest that future global GPP dynamics would be more influenced by climate change than LULC change. The dramatic GPP loss under the RCP8.5 scenario since especially 2050 indicates a potential risk of locked-in environmental degradation in a future with high energy demand and carbon emissions yet without any climate mitigation policy. 

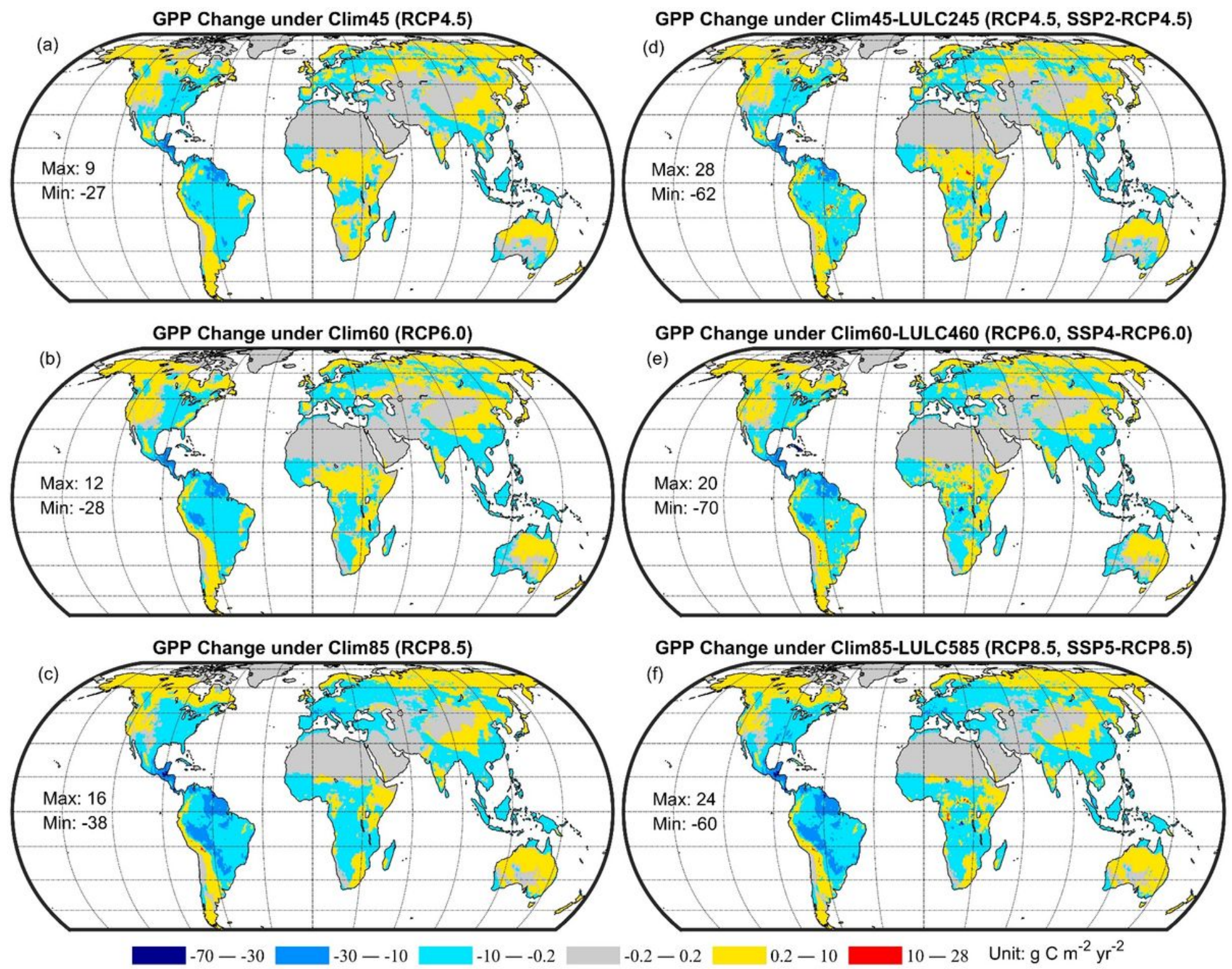

Figure 7

Global patterns of annual GPP change during 2015-2100, simulated by only changing the climate input in CoLM (left panel) and by changing both the climate and LULC inputs (right panel). a Clim45, b Clim60, c Clim85, d Clim45-LULC245, e Clim60-LULC460, f Clim85-LULC585. Similar to Fig. 4, the annual GPP change for each grid is computed based on the Sen's slope of the GPP projections for every five years from 2015 to 2100 . Unlike Fig. 4, the majority of the world would experience non-trivial GPP changes (i.e., non-gray areas), with mostly the desert areas having relatively stable GPP (i.e., gray areas). Further, horizontal comparisons (left vs. right) consistently suggest that LULC change would not notably change the spatial pattern of global GPP, while vertical comparisons (upper vs. middle vs. lower) consistently suggest that climate change would markedly expand GPP loss areas. 

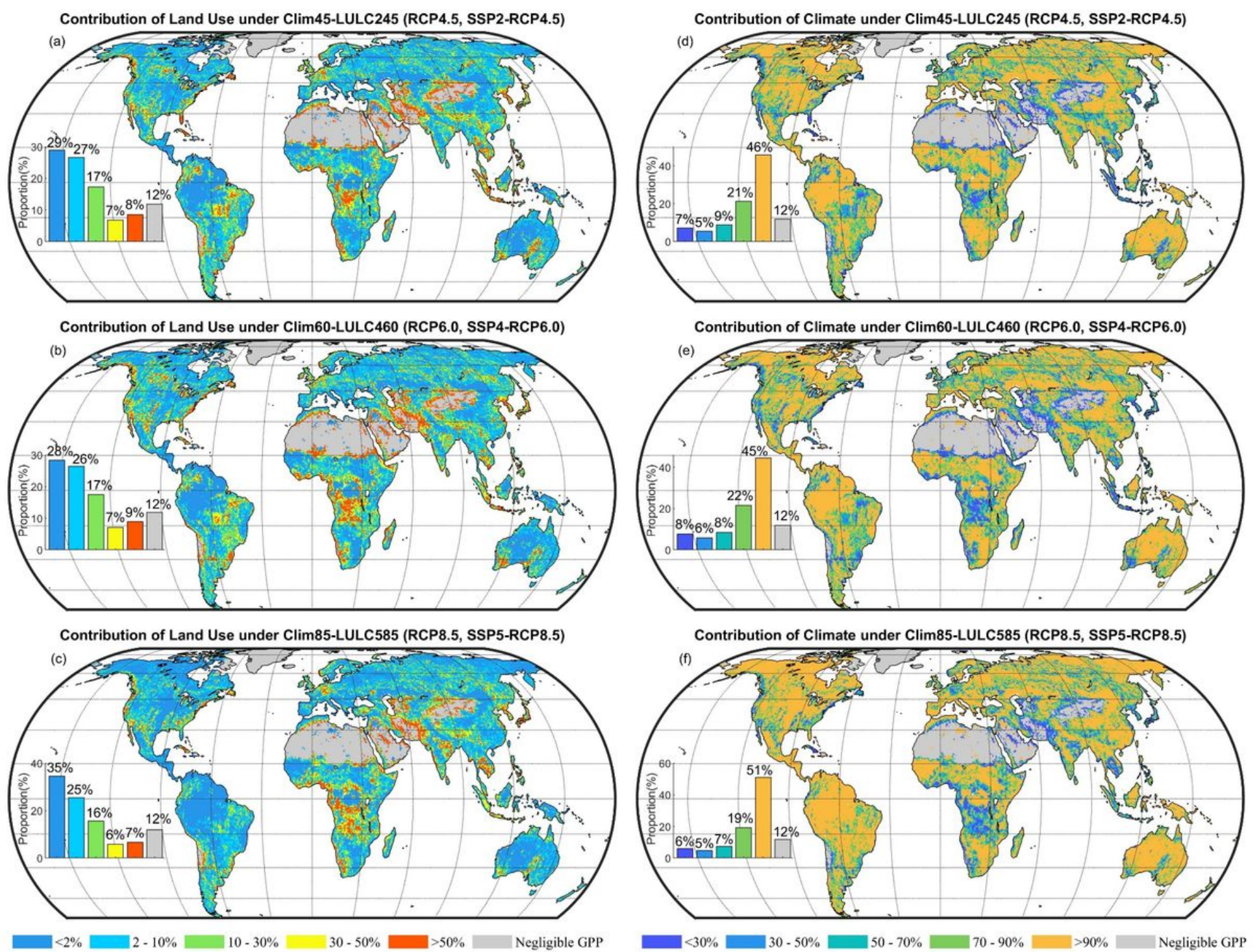

\section{Figure 8}

Secondary yet non-trivial impact of LULC change on global GPP dynamics during 2000-2100, compared to that of climate change. Left: contribution of LULC change to GPP dynamics for each $0.5^{\circ}$ grid under a Clim45-LULC245, b Clim4-LULC460, and c Clim85-LULC585; Right: contribution of climate change to GPP dynamics for each $0.5^{\circ}$ grid under d Clim45-LULC245, e Clim4-LULC460, and f Clim85-LULC585. The bar graph in each subfigure shows the proportion of the global terrestrial area by contribution level of LULC/climate change. Note that the spatial pattern of the places with LULC change dominating GPP dynamics are somewhat fragmented yet relatively stable.

\section{Supplementary Files}

This is a list of supplementary files associated with this preprint. Click to download.

- Supplementaryinformation.docx 